African Research Review vol.1(1)

\title{
An Appraisal of the Performance of the Nigeria's National Rolling Plans in the 90's O.C. UKAH
}

\begin{abstract}
The performance of the rolling plan since its inception has been one of mixed grill. Despite the instability of the oil revenue on which most of the plan relied on, the rolling plan could be said to have made some impact in Nigeria's economic scene. The paper examines the performance of the financial sector and real sector in line with the national rolling plans vis-à-vis the yearly budget targets of the nation. It was noted that over the years, the remarkable progress made in the 1970s has been reversed sharply with rising incidence of poverty and malnutrition, alarming decline in educational standards and income distribution. The paper concludes that, in Nigeria, planning has not been the problem but that of translating plans in to realities. It gives possible policy options to match plan targets within the limits of the available resources.

Introduction
\end{abstract}

Nigeria has for the past four decades adopted systematic economic development planning as means of speeding up the growth rate of the economy and improving the living standard of the teaming population. In fact Nigeria has implemented four fixed medium term national development plans, the $1^{\text {st }}$ national development plan lasted from 1962- 68, the $2^{\text {nd }}$ from 1970-74, the gap was as a result of civil war which end in 1970 , the $3^{\text {rd }}$ was from $1975-80$ and the $4^{\text {th }}$ from 1981-85. The fifth was to be lunched at the end of 1985 but due to the prevailing economic crisis and the socio-political scenario, it was abandoned. In all, specific emphasis has been placed on planning because of the urgent need to rationally tap the available scarce resources for the socio-economic development of the nation.

Instead of having a $5^{\text {th }}$ development plan to cover the period 1986-90, Nigeria adopted a policy plan, the structural adjustment programme (SAP) which was initially designed to last from 1986- 88 but which was later extended to last till 1990.

During the formulation of the abandoned $5^{\text {th }}$ plan, a major change in planning strategy in Nigeria was introduced. Government decided on a 15-20 years perspective plan for the period 1990-2009. This is as a result of the fact that limiting the time range of development plan to 5 years had not allowed for long term assessment of the problems of the economy. Consequently, the shift in strategy was as result of huge resource shortfalls which severely affected the performance of the $4^{\text {th }}$ plan. Most significant among these problems are inadequate level of foreign exchange to service debt and sustain meaningful growth and development, high level of inflation and unemployment and a weak growth of the productive sector.

In the light of this, a new economic planning framework in Nigeria's economic management emerged. The traditional $5 \mathrm{yr}$ planning model gave way to a 3 - year rolling plan to be operated along with 15-20 year perspective plan and the usual operational annual budget. The three planning circle i.e. perspective plan, rolling plan and annual budget became operational in 1990. It is in the light of this that, this write up will examine the achievements of the rolling plan, which was aimed at actualising the objectives of the perspective plan. However in assessing the achievement, various past budget target were use to analyze the effectiveness of the rolling plans.

Basically it has been identified that the five year plan has some inherent problems. Therefore, the nature of the fundamental problems which featured in the implementation of fixed medium term plans put in place between 1962 and 1985 could only be resolved 
in the long term. This write up is aimed at assessing the achievements of the long range 15-20 year plan operated through the rolling plans by taking a critical analysis of the performance of the rolling plans from 1990-97.

Since the fixed 5-year plan has been abandoned as a result of economic exigencies, the rolling plans has taken over from 1990 to the present day. What amount of success has been achieved so far? Is there any out standing radical departure in terms of plan achievement from the fixed plan? This write up will attempt to examine these issues enumerated.

This paper takes an indebt examination of the macroeconomic variables in the Nigerian economy, such as national accounts aggregates, public finance, external transactions and monetary aggregates. In other words, the study examines the performance of the financial sector and real sector vis-à-vis the yearly budget targets of the nation.

\section{Literature Review}

In this section, various literature on national planning in Nigeria since the colonial era will be briefly x-ray and an appraisal of the recently adopted rolling plans will be made.

A vital tool for managing the growth in the economy is development planning in Nigeria, developing and developed world at large. According to Olaniyan (1997), national development planning in operational term therefore, is the process of setting goals and targets for economic and social development, formulating policies, programmes and projects for the attainment of such goals and mobilizing and deploying resources for their effective implementation. It is a decision in advanced of what has to be done, who has to do it, when it has to be done and how it is done in order to bridge the socio-economic gap from where we were to where we want to be.

Development planning could be imperative in which all economic activities and resources are directly under the control of the state. It could also be indicative in which case government does not directly control the private sector but provides the necessary facilities and indicates the areas in which the sector can assist in implementing the plan. Planning could equally be democratic; here the people are involved at every level in plan formulation/design and execution.

\section{Emergency of rolling plan in Nigeria}

Nigeria has had about six decades of development plan, pre-independence inclusive, in actual fact she has had precisely four decades of national development planning after her independence. The economy has achieved some measures of positive growth, the achievement is rather negligible when compared with the volume of resources earmarked and expended by the country over the periods.

The first development plan came on stream in 1944, when the secretary of state for the colonies requested the government of all British colonies to formulate plans for the economic and social development of their territories. The plan was referred to as "Tenyear plan of development and welfare for Nigeria". A total plan expenditure of about N110.00m for a period of ten years was envisaged from April 1, 1946 to $31^{\text {st }}$ march 1956. out of this planned expenditure, $\mathrm{N} 46 \mathrm{~m}$ was to be met with funds provided under the colonial development and welfare act. 
The main focus of the plan was on building infrastructure with little provision for industrial development. Attention was centred in terms of agricultural on a limited range of crops e.g. cocoa, cotton, palm produce, groundnut and timer log.

In the words of Ayo (1988), the ten -year plan could hardly be regarded as a development plan in any serious sense. It was more of a list of projects, the selection and preparation of which did not take cognisance of the participation of the population being planned for. However, the adoption of federal system of government in Nigeria in 1954 brought the plan to a abrupt end. With the granting of autonomy to each of the regional government in 1955, each of them and the federal government lunched its own 5- year development plan for the period 1955-60. After a lot of review, the estimated total cost of the programme was about N328m. Actual expenditure federal wise was mainly on highways and bridges, public works, post and telegraphs amounted to about N292.8m. In terms of economic achievements, growth estimates shows that the economy grew at an average of $4 \%$ per annum in real terms in the decade 1950-60.

The first national post independence development plan was launched in June 1962 to cover a period of 7 years under the plan, a total investment expenditure of about $\mathrm{N} 2,132 \mathrm{~m}$ was projected. Out of this public sector investment expenditure of N780m was expected to be undertaken by the private sector. A target growth rate of $4 \%$ per annum was set for the first time in the economy of Nigeria. In spite of the civil war interruption in 1967, many of the major projects embarked up on in the plan period were successfully completed. The overall performance of the economy was impressive. On the whole, the economy achieved a 5\% annual growth rate.

The $2^{\text {nd }}$ national development plan 1970-74 was launched shortly after the end of the civil war as a means of repairing a war-devastated economy, promoting socio-economic development in the country. The plan marked the very first attempt to express a social philosophy that should guide the plan. The philosophy as spelt out in the objectives which were to establish Nigeria firmly as:

i) a united, strong and self-reliant nation;

ii) a great and dynamic economy;

iii) a just and egalitarian society;

iv) a land of bright and full opportunities for all citizens and

v) a free and democratic society.

The $2^{\text {nd }}$ national development plan was much bigger in size and more diversified in scope than any plan Nigeria had. It was also the first plan to be adequately integrated, a total capital expenditure programme of about N4.00bn, was to be undertaken. Out of this, the proposed public sector investment was $\mathrm{N} 3.3 \mathrm{~b}$ while private sector was expected to make an investment of N1.6bn. In terms of targets, it was expected that the above investment would amount to increase growth in the gross output of the economy from a level of $\mathrm{N} 3.028 \mathrm{~b}$ in $1969 / 70$ to N3.987b, by the end of the plan period. Although, the economy was expected to grow at an average rate of $6.3 \%$ per annum in the period. However, actual estimates showed that the GDP at 1974/75 factor cost rose from N9. 442b in $1970 / 71$ to $\mathrm{N} 14.410 \mathrm{~b}$ in $1974 / 75$ indicating an average growth rate of about $11 \%$ per annum.

The $3^{\text {rd }}$ national development plan $1975-80$ follow the pattern of the $2^{\text {nd }}$ plan. The plan initially had a total investment of about N34bn for the whole economy with N24bn earmarked for the public sector and N10bn for the private sector. The public sector 
programmes was later revised to cover N43.3bn, this is ten times the quantum of the $2^{\text {nd }}$ plan and fifteen times that of the first. According to Ayo(1988), by all standard the plan was an ambitious one whose aim was to use the earning from crude oil exports rapidly to accelerate the development of the productive capacity of the economy. The first two previous plans had projected an average growth rate of $4 \%$ respectively in real terms for the economy, while the $3^{\text {rd }}$ plan projected an average growth rate of $9.5 \%$. The plan placed high priority on the development of basic industries, infrastructure and social services particularly education and health.

The five cardinal objectives of the $2^{\text {nd }}$ plan were expanded in to seven more specific objectives and these includes;

i) increases in per capita income,

ii) more even distribution of income,

iii) reduction in the level of unemployment,

iv) increase in the supply of high level manpower,

v) diversification of the economy,

vi) balanced development and

vii) Indigenization of economic activities.

The plan execution was gravely distorted by the slump in international oil price in the world market and also from protracted loan negotiations with the multinational financial institutions e.g. world bank. The change in government in 1975 hinder the rate of effective plan execution. In addition, the state creation increased the pressure on the tight financial resources that were earmarked for the plan implementation. However, in spite of the falls in revenue estimates. The picture was that the GDP at 1977/78 factor cost grew from N27.4bn in 1975/76 to N35.2bn in 1979/80. As compared with the target growth rate of about $9.5 \%$ it represents an average growth rate of $6.5 \%$ per annum.

The $4^{\text {th }}$ plan 1981-85 designed under a democratically elected government based on the presidential system had a projected capital expenditure of about N82bn. in terms of comparison the plan was far much bigger than previous plans. The plan had in addition to the stated seven objectives in the $3^{\text {rd }}$ national plan the following;

i) greater self-reliance,

ii) development of technology,

iii) increased productivity and

iv) the promotion of a new national orientation conducive to greater discipline, better attitude to work and cleaner environment.

The plan execution was frustrated by the collapse of the international oil market. Oil output fell by $43.5 \%$ to $1.3 \mathrm{~m}$ b.p.d. instead of the estimated $2.3 \mathrm{~m}$ b.p.d. Crude oil price fell by $25 \%$ to $\$ 30$ p.b. instead of the plan estimate of US $\$ 40$ p.b. As a result, there was a fall of $25 \%$ foreign exchange receipts. Public sector investment was therefore, financed through huge deficits incurred from commercial banks, central Bank of Nigeria and local contractors. Consequently, there was a great increase in number of abandon uncompleted projects all over the nation. Our external debt liability increase from an estimate of N3. 7 bn in 1981 to N17. 3bn at the end of 1985 indicating a rise in debt service ratio from $4.7 \%$ in 1981 to $31.7 \%$ in 1985 . In fact, by 1985 Nigeria's external reserves have run close to a level that could hardly finance 
more than one and half month import bills. Domestic debt outstanding more than doubled from N11.4bn in 1981 to N28. Obn in 1985.

The economy's showing during the $4^{\text {th }}$ plan period was generally poor. Available estimates showed that the economy with a base of N30. 3bn GDP at 1977/78 factor cost in 1980 and which has been expected to grow at about $7.2 \%$ per annum during the plan period decline in growth rate to about $9.0 \%$ per annum.

In the words of Gali (1997), the plan was intended to further the process of establishing a solid base for the long run socio-economic development of Nigeria.

Rather than continue with the fixed 5-yr medium term plan or have a fifth plan in the series, the country adopted a policy plan, i.e. the structural adjustment programme. It was initially designed to cover the period 1986-1988, but later extended to provide the policy basis for the successive 3-yr rolling plans which commenced in 1990 and has been operational till date. The change in planning model was as a result of the huge short falls in expected earnings from oil which adversely affected the performance of the 1981-85 development plan. It became obvious that the country could no longer rely on the fixed term 5-yr plans in a situation where the economy had become subject to the vagaries of the international oil market.

The background structural adjustment programme was designed to arrest the problems that featured in the economy emanating from the huge shortfalls in oil sector receipts, including persistent fiscal deficits, huge deficits in the balance of payment account, huge backlog of on going uncompleted projects and a high incidence of external debt service resulting from a rapidly rising level of external indebtedness. Olaniyan (1997) stated that it was the consideration of the enumerated problems above that prompted a new economic planning framework in the country's national economic management in the Rolling plan. He further stated, that the system in a 3-tier system of planning in Nigeria comprising;

i) a fifteen to twenty (15-20) year perspective plan that would provide a clear vision of where the economy should be at the end of the period and pursue appropriate set of policies and programmes that would lead to the achievement of the desired goal;

ii) a 3-yr Rolling plan which derive its bearing from the perspective plan and be subject to annual modification to take account of rapidly changing internal and external environment as well as resources profile of the economy;

iii) an annual budget which would drew its inspiration and programmes from the Rolling plan.

It is believed that this planning model is better adapted to accommodate project and programmes with long gestation periods, provides desired vision for the economy, enabling private investment to respond more positively to short-term fluctuations. It is in the light of the foregoing that this write will examine the achievement of the rolling plans so far.

\section{The perspective plan, Rolling plan and Budget-relationship}

The perspective plan- the perspective plan of a nation is not expected be isolated from the medium term plan and annual budgets. In principle, the succession of planning tasks over different periods should from a single unbroken chain, each link 
of which has its own well-defined role to play. The perspective plans have longer time horizon say 15-20 yrs duration.

The institutionalization of the perspective plan is believed will help in achieving the following;

i) examine the long term development options open to the Nigerian economy;

ii) identify possible bottlenecks that may occur during the period say $15-20$ years;

iii) offer possible solutions in terms of policies and programmes;

iv) determine the pattern of future investment in the key sectors of the economy and

v) Address policy measures necessary to achieve the set policy targets.

Rolling plans - In a rolling plan, the plan is reviewed continuous on annual basis and as the first year of the plan is dropped, estimates, targets and projects for another year are added to the last year. It is therefore, difficult to talk of the expiration of the life span of a rolling plan. For instance, the 1990 federal budget will be the tool for executing the launched 3-yr national Rolling plans programmes in its first year. At the end of 1990, the rolling plan was reviewed in a manner to roll it over to include 1993 while dropping from its scope 1990, which was its initial year. This implies that for each succeeding year, the plans were rolled over. The rolling plan in 1990 had a scope covering 1990-91-92 while the rolling plan in 1991 spread over 1991-92-93. A similar procedure would be followed at the end of every year thereafter. Nigeria has decided to adopt this mode for the following reasons:

a) it is more down to earth, avoids the pitfalls of a 5-yr plan which tends to stray away from reality.

b) Rolling plans corrects the inadequacies of the one- year budget, which fails to capture projects with invariably more than one-year completion period.

c) It possesses the adopted effect of raising the level of consciousness for accurate data and regular supervision by project management units.

Annual plan or budget deals with current development activities without losing sight of longer-term goals. A typical annual operational plan starts with an account of the progress of the medium term plan in the previous year. A comparison is made between planned and actual development to date and the reasons for deviation from targets are analysed. The more important projects to be carried out during the current year, along with the estimate of cost and available resources are specified. The most important aspects of an annual plan describes the particular monetary, credit, wage, fiscal and other measures to be adopted during the year to achieve the annual targets.

According to Waterston (1965), annual plans are used mostly as recurrent instruments for detailing exactly what must be done to convert existing medium term plans in to programmes for action. The fundamental relationship is that the annual plan (budgets) with particular references to the capital programmes forms the machinery for implementing the 3-yr national Rolling plan. In effect, the capital programmes contained in the 1990 budget should be the same as that in the first year of the rolling plan. The 
same similarity is expected every year. Consequently, the relationship between the rolling plan and the annual budgets is very close. The rolling plan run as an instrument of overall control providing the main frame for the yearly budget which is used to adjust plan estimates to synchronize with any revised government priorities and new economic realities. In this regard according to Edozien (1990), there is hardly any conceptual separation between the rolling plan and the budget as the latter indeed forms the background for revising the former. Therefore, the rolling plan in reality assumes the nature of a multi-year budget framework. The rolling plans are, however, to constitute specific phases of the perspective plan. The three units of planning can be clearly as been interwoven.

\section{Achievements and Problems}

The rolling plans in Nigeria are to draw inspirations from the broad goals and objectives of the vision 2010, which include forging a plan, which will by the year 2010, facilitate, Nigeria becoming a developed nation in terms of economic prosperity, political stability and social harmony.

The broad policy aims of the national rolling plan include achieving real economic growth and macro-economic stability among other objectives in order to alleviate the problems of unemployment and poverty in the society.

Attempt is made here to examine the performance of the economy since the adoption of the national rolling plan.

A close examination of the national account since the 70s to the period under review shows that over the years, the GDP at 1984 factor cost has a showing, the increase has been marginal, from N54, $148.9 \mathrm{~m}$ in $1970 / 71$ to $\mathrm{N} 68,916.1 \mathrm{~m}$ in 1985 (pre-SAP), to N90,342 at the end of the first year of the rolling plan, and to N103,510m after 6 years of implementation of the rolling plan. However, a critical examination of the GDP at current market prices reveals that the growth rate over the years has been glaring. In real terms, it increased from modest value of $\mathrm{N} 21,558.8 \mathrm{~m}$ in $1975 / 76$ to $\mathrm{N} 72,355.4 \mathrm{~m}$ in 1985 (pre$\mathrm{SAP}$ ) to N260,636.7m at the end of the first year of the rolling plan and N1,997,740m in 1995 after a 6 year period of rolling plan implementation. The reasons for the noticeable increase can be attributed to the increase in economic due to the fall in exchange rate value of the naira to the major international currencies, e.g. $\$$ and $£$. Consequently, the increase may not reflect the real worth of goods and services when compared with the pre-SAP exchange rate of 1985 and beyond.

There has been a fluctuating trend in the gross fixed capital formation (GDFCF) before the SAP era, after which there has been a moderate increase from N5,573m in 1985 to $\mathrm{N} 18,414.1 \mathrm{~m}$ in $1989, \mathrm{~N} 30,826.8 \mathrm{~m}$ at the end of the first year of the rolling plan and N367,510.0 after 6 years of the rolling plan.

However, in percentage terms, the table below clearly illustrates the scenarios of gross domestic investment and consumption since the rolling plan came in to existence.

Table 1: Nigeria's gross domestic investment and consumption 1989-96.

\begin{tabular}{|l|l|l|l|}
\hline Year & $\begin{array}{l}\text { GDFCF \% of } \\
\text { GDP }\end{array}$ & $\begin{array}{l}\text { GDFCF of } \\
\text { annual growth rate }\end{array}$ & $\begin{array}{l}\text { Private and government } \\
\text { consumption \% }\end{array}$ \\
\hline 1989 & 5.1 & - & 79.6 \\
\hline 1990 & 6.3 & 35.5 & 75.3 \\
\hline 1991 & 5.8 & -3.5 & 81.9 \\
\hline 1992 & 5.7 & 0.9 & 85.4 \\
\hline 1993 & 6.2 & 10.9 & 85.1 \\
\hline
\end{tabular}




\begin{tabular}{|l|l|l|l|}
\hline 1994 & 5.8 & -5.0 & 87.1 \\
\hline 1995 & 6.0 & 6 & 88.7 \\
\hline 1996 & 5.8 & - & 87.5 \\
\hline 1997 & 5.4 & & 85.2 \\
\hline Average & 5.8 & 6.2 & 83.8 \\
\hline
\end{tabular}

Source 1.CBN Bulletin vol.7 (1996) 2. CBN Bullion vol.21(1) 1997

The trend of the GDFCF in terms of the GDP and annual growth rate portrays a gloomy picture of the economy. In the words of Obadan (1998),

Nigeria's public investment has performed dismally over the past two

decades, public investment performed much better in the pre-SAP era. Available statistics shows that with the exception of a few years the percentage share of gross fixed capital formation in GDP has been on the decline since the 1970s. It is share which averaged $25.8 \%$ from 1975-79, declined to 16.1, 9.6 and 5.9\% in 1980-85, 1986-90 and 19911996 periods respectively. Indeed, from 1989 to 1996 the share of GDFCF in GDP averaged only 5.8\% compared to an average share of $83.8 \%$ for private and public consumption.

With Nigeria's investment rate falling far below 20-25\% of the GDP as attained by the economies of the East Asian tigers, which aided them to attain 7\%-8\% GDP growth rate, the $5.8 \%$ investment share of the GDP is too small to generate meaningful economic growth.

A closer examination at the GDP at current factor cost since the 80 s to the period under review clearly shows that the petroleum sub sector has been domineering in the scheme of things. It has more than doubled its share before the adoption of the rolling plan. It rose from N12110.1m pre-SAP to N78,788.1m at the end of SAP to N86,188.0m at the end of the first year of the rolling plan and N792,370.0m after a period of 6 years implementation of the rolling plans. Agriculture which employs about 2/3 of the nation's labour force has been relegated to the $2^{\text {nd }}$ position with a contribution of $N 19,729.0 \mathrm{~m}$ in 1985 (pre-SAP), N56,577.4m at the end of SAP in 1989 and N68,416.7m at the end of the first year of the rolling plan in 1990 and N527,470m after 6 years implementation of the rolling plans. The showing of the manufacturing, finance and insurance sub sectors are in no way better.

Consequently, the picture has been one of heavy reliance on the petroleum sub sector. The performance of selected macro-economic indicators in percentage terms, clear reveals that growth in money aggregate had by far exceeded the planned targets over the rolling plan period 1991-96. Consequently, proving the weakness of the monetary policy implementation. The fiscal deficit ratio has improved over the years showing the public sectors prudent management of resources. However, the growth rate of the GDP has remained virtually low over the years decreasing from $4.7 \%$ to $1.3 \%$ in 1994 and again $3.3 \%$ in 1996.

The manufacturing sector though relatively stable over the years, has been operating below the installed capacity while the rate of inflation has become astronomically high from $13 \%$ in 1991 to about $72.8 \%$ in 1995 but later decline to $29.3 \%$ in 1996.

The overall balance of payment position has nothing to show for it. It has virtually been in deficit over the planned period. The external reserves over the planned period 
have been dwindling. In actual fact, the rolling plans have not performed significantly better than the 5-year fixed plan.

\section{Problems of plan implementation}

A lot teething problems have been identified as militating against effective monitoring and appraisal of projects and programmes during plan implementation process.

These include

i) the corrupt tendencies of government representatives and contractors has tended to lead to the untimely death of most projects as the resources meant for such projects are siphoned in to private pockets through over invoicing, inflated contract cost and kickbacks.

ii) A lot of the plans have been unrealistic in terms of their scope, resource availability and output. This has been responsible for the non-realisation of the targets.

iii) Slow pace of sectoral transformation reinforced by the structural weakness of the economy as illustrated by the persistent dominance of primary production in GDP and over reliance on the petroleum sub sector which can not assure long term growth of the economy.

iv) Political instability resulting in frequent changes of government and policy priorities. This has ended up in projects and programmes being abandoned after a colossal amount of scarce resources have been invested.

v) Inadequate executive capacity among projects implementation agencies have led to poor projects execution, control, co-ordination, supervision and linkages at various levels.

vi) The flexible nature of the rolling plan has encouraged lukewarm attitude in plan execution since projects could easily be rolled over without any probing eye questioning it.

vii) Shortage of funds and delays in capital release to projects has serious cost implication for projects completion. This has resulted in unplanned increase on initial estimates of project cost.

\section{Conclusion}

The performance of the rolling plan since its inception has been one of mixed grill. However, in view of the instability of the oil revenue on which most of the plan relied on, the rolling plan could be said to have made some impact in Nigeria's economic scene. According to Usman (1998), most economic fundamentals moved in the right direction during the fiscal years 1996-97. The inflation rate declined from $29 \%$ to $8.5 \%$, GDP showed positive growth and there was exchange rate stability.

It is vital to note that over the years the remarkable progress made in the 1970s has been reversed sharply with rising incidence of poverty and malnutrition alarming decline in educational standards and income distribution. In Nigeria, planning has not been the problem but that of translating plans in to realities.

To ensure that by the year 2015 Nigeria has come of age economically, socially and politically. There is the urgent need to match plan targets within the limits of the available resources. Experience has showed that the larger the plan the more difficult it is 
to attain the target in recorded time given the attendant inflationary pressure of the cost of project execution.

Implementation of plan is even more important than planning itself; plans have to be translated into realities. Therefore, adequate resources should be committed to projects in terms of personnel and funding. Experts are required to effectively and continuously monitor and evaluate programmes, identifying various problems and needs to ensure speedy execution of projects. Again, capital releases should be timely to ensure cost effectiveness in projects execution.

The political atmosphere should be stable. The frequent changes in governance do not augur well for continuity of projects and programmes. There is also the urgent need for credible, consistent and stable macro-economic policies. This will ensure positive indicators on the economy, consequently improving the credit rating for investors.

Capacity deficiencies should adequately be addressed through human capital development and retention leading to effective use of labour and material capital. Transparency, especially in the public sector needs to be promoted, as it reduces the cost of projects and provides a conducive environment.

\section{References}

Ayo. E.J.(1988), Development planning in Nigeria

Ibadan University Press Limited.

Gali C.D. (1997), The Nigerian experience in national Economic planning; plan, Design. Implementation and monitoring $C B N$-Research seminar paper No.2.

Obadan M.I. (1998) President's welcome Address at the $39^{\text {th }}$ Annual conference the Nigerian Economic Society Newsletter vol 39. No1

Olaniyan I.F (1997) Concept framework, issues and national economic development planning CBN-Research seminar paper No. 1

Usman I. (1998) "Budget" designed to play solid foundation for fiscal discipline. The Post Expresses No 996 Jan. 6.

CBN (1997) BULLION vol 21 no 1

CBN (1996) Statistical bulletin vol. 7. 